\title{
A planetary turn for the social sciences?
}

\author{
Bronislaw Szerszynski
}

\section{DRAFT - please do not quote or cite without permission}

\author{
Chapter written for Sven Kesselring, Ole B. Jensen and Mimi Sheller (eds) (forthcoming) \\ Mobilities and Complexities: Reflections on Post-Carbon Social Science (working title), \\ London: Routledge.
}

In the 1990s sociology, like many other social sciences, underwent a global turn, with an explosion of interest in social dynamics beyond the borders of nation states. This was partly driven by a wide sense, growing through the 1980s, that the social world was changing in ways that demanded new concepts and priorities. The surface of the globe was becoming more interconnected; if it had ever been possible to have a meaningful bounded study of a local or national society, this was becoming ever more implausible. With the steady growth of global travel and communications, the emergence of an integrated global economy based on regional specialisation, and the increased intermixing of cultures and staging of mediated mega-events, the proper object of sociology seemed to be becoming a global society. More haltingly, there was also growing awareness that what needed to be globalised is not only the object of sociology but also the set of intellectual ideas and concepts used to study it, which were still overwhelmingly dominated by intellectual and political perspectives developed in Europe and North America. John Urry was a key figure in this global turn: in his books with Scott Lash, The End of Organised Capitalism (1987) and Economies of Signs and Space (1994), and then more explicitly in Sociology Beyond Societies (2000), John argued that the object of sociology was changing, no longer bound together into settled, national societies, and that sociology needed to change in response. The project on global citizenship, cosmopolitanism and the media that John and I carried out with Greg Myers and Mark Toogood in the 1990s on global citizenship illustrated well that direction.

But in John's work there were also hints of another potential transformation of the social sciences, one which I want to call the planetary turn. While sharing some themes with the global turn, this nascent turn is strikingly different in its approach and implications. Above all, whereas the global turn was mainly about saying that the social sciences needed to respond to the growing interconnectedness of social processes across the surface of the planet, the planetary turn involves the recognition that the bounding of the social was always already problematic, and on another, more comprehensive front: that between human society as a semiotic, meaningful phenomenon on the one hand and the physical processes of the Earth on the other. It thus involves the rejection of what had been a key assumption of sociology since its foundation, human exemptionalism, an assumption which had already been problematized in the 1970s by the subdiscipline of environmental sociology with which John became increasingly engaged (see Contested Natures with Phil Macnaghten (1998), Climate Change and Society (2011) and Societies Beyond Oil (2013)). John thus added his voice to the growing call in sociology, anthropology and science and technology studies for more attention to be paid to the social significance of material things and processes. Most explicitly, he called in Sociology Beyond Societies (2000) for 'new rules of sociological method' that abandoned the notion of an a priori difference between humans and the objects with which their social lives are entwined, and across many of his works showed how in this task the social sciences could productively draw on perspectives from the physical sciences, especially from thermodynamics, theoretical biology and complexity theory (see for example Global Complexity (2003), Mobilities (2007) and Climate Change and Society (2011). 
While John engaged with many planetary themes in his later work, and made many of the theoretical moves necessary for a sociology that takes our planetary condition seriously, he left it to others to put this all together as a fully-fledged programme for the social sciences. It is largely amongst social science and humanities scholars engaged with the concept of the Anthropocene, Gaia and the Earth system that this kind of work is being done (e.g. Clark 2011; Connolly 2017; Hamilton 2017; Latour 2017; Tsing et al. 2017); however, this remains a very heterogeneous field. In the rest of this short article, I will try to spell out what I think are the key steps involved in what is still unfinished business for the social sciences - a planetary turn. In so doing I will try to tease out some of the origins of my own planetary thinking in John's work.

Firstly, the foundational task of any planetary turn must be the interdisciplinary task of investigating the planet as a category of being in its own right, and the ways in which this conditions social existence in fundamental ways. This involves moving beyond the way that the figure of 'the planet' has figured in globalisation discourses, where the focus has been on a narrow range of characteristics of the Earth such as unity, boundedness, fragility and interconnectedness. Instead, we need a more complex account of 'planetary being' which is at once more general and more tightly specified. John's use of complexity, emergence and non-Newtonian time in books from Sociology Beyond Societies (2000) onwards was a great starting point, but we need to draw in more detail from the Earth sciences.

For example, planets are made up of condensed, classical baryonic matter (i.e. 'normal' atoms), comprising a range of chemical elements and existing typically at a mid-range of temperatures between the cold of space and the huge temperatures of stars, and thus able to compose itself into complex entities with a deep compositional hierarchy (e.g. gases, molecules, atoms, subatomic particles) involving different properties and dynamics at each level. Planets are also gravitationally collapsed and differentiated, so that they form dense, approximately spherical bodies with their own gravitational fields (and hence a vertical dimension) organised internally into different strata and compartments; they also dominate an orbital region around their star and interact with each other to produce relatively stable orbits over long timescales. They are also (more or less) materially closed but energetically open, subjected to flows of energy over long timescales from their parent star and hot interior, which energy has to cascade through nested interacting subsystems before being discharged as long-wave radiation into space. These dynamic features, combined with the specific circumstances of their formation and development, means that planets become unique historical entities, capable of generating new kinds of phenomena that interact in complex ways on different timescales. A planetary social science would be aware of how these features of planets at once make possible and also condition human life. Such a 'planetary posthumanism' would situate what are taken to be the distinctive features of human social life society, language, meaning, cognition, action, technology - within a more comprehensive picture of how new forms, powers and kinds of relation arise under planetary conditions.

Secondly, it follows that a planetary social science would be volumetric, concerned with relations not just on the surface of the Earth but also within and across all the different entangled volumes of the planet from its core out to its near space environment. As social scientists are increasingly arguing, we need to develop a 3D imaginary for the social sciences. John's work gave some pointers for how to do this, by going up into the atmosphere in his book with Cwerner and Kesselring on Aeromobilities (2009) and down into geological strata in Societies Beyond Oil. But this volumetric approach needs to be developed more systematically, through a deeper engagement with the significance of the Earth's stratification into different layers and compartments - core, mantle, crust, biosphere, hydrosphere, atmosphere, magnetosphere - with different properties and stabilised on different timescales.

A planetary turn would also be concerned with the distinctive topological relations and thereby modes of existence and relatedness that are made possible by this stratification. Strata are often in asymmetrical relations of dependency with each other, and the surfaces and boundaries between different strata and compartments occasion radically different kinds of phenomena. The 
sub-aerial surface that was left largely reified and unproblematised in sociology's global turn starts to look different and far more interesting when we first zoom out to investigate the diverse forms of complex order that can be generated in and between other zones of the extended body of the Earth, and only then zoom back in to the 'critical zone' or 'boundary layer' of mixing between earth and sky that we ourselves inhabit.

Thirdly, a planetary social science would also have to engage with the interplanetary. One aspect of this concerns interplanetary mobilities - the study of the multiple ways in which the stories of individual planets can become intertwined through the exchange of entities and materials of different kinds. Here the critical social sciences can help avoid the unreflective projection of 'globalisation' narratives of imperialism and neoliberalism onto an extra-terrestrial canvas. But another aspect of the interplanetary, at least as important, is the comparative. The deepening understanding of our own solar system and the continuing discovery of diverse exoplanets orbiting other stars can help us to construct a far more expansive theoretical 'phase space' for planetary development, one that can accommodate diverse possible developmental trajectories of planets. For the social sciences this is an opportunity to counter the dominant geocentric 'observer bias' that takes the specific story of the Earth to be the template for any planet that might develop complex organised matter. Drawing on empirical astronomy, but also the more speculative practices of astrobiology and science fiction, a planetary social science can explore how the complex forms of matter, meaning and motion that we associate with society might have emerged through very different developmental processes and take profoundly different forms.

However, this comparative move is also one that should make us look at our own planet differently, as itself 'alien'. The Earth, and indeed any other planet, becomes what it is through becoming other to itself, on a number of timescales. As geologist Jan Zalasiewicz puts it, on the longest timescale, 'the Earth seems to be less one planet, rather a number of different Earths that have succeeded each other in time, each with very different chemical, physical and biological states'. But planets such as the Earth are also constantly involved in the internal generation of otherness; especially within the fluid elemental media of planets, alterity is immanent (internal to the region), gradual (manifests as gradients) and generative (constantly producing form and new gradients). Zones on apparently very different planets can also have more in common with each other with each other than with zones on the same planet. Thus relations of difference between and amongst our planets are not merely external but internal; and relations of difference and alterity do not just divide planets from each other, but can also divide planets from themselves - and conjoin them with each other. To adapt the language of Sarah Whatmore and Marisol de la Cadena, to think about and through the Earth is therefore always already to think of it as 'more than' Earth, as the Earth 'but not only'.

Fourthly, a planetary social science would also be temporally extended into the deep time of the Earth, concerned with the geological and astronomical timescales of what John called 'glacial time'. Fernand Braudel's longue durée needs extending further into planetary history - not in order to diminish the importance of contemporary environmental changes but to recontextualise them. Planets as open systems maintained far from equilibrium and driven by thermodynamic imperatives pass through a number of irreversible 'bifurcations', 'major transitions' or moments of symmetrybreaking, which involves them arranging themselves in new ways and developing according to new logics. Attending to the geohistorical details of these transitions can reveal many social processes and dynamics to be examples of long-standing patterns in material differentiation and association in the history of the Earth. Furthermore, just as John taught us that glacial and instantaneous time can coexist in the same social formation, alternative possible metastable states of the Earth can neither be divided unproblematically into those that are actualised and those that are never actualised, and the former simply arranged in a non-overlapping sequence; instead, all possible states of the Earth, even if 'real but not actualised', are in some sense active and confronting each other at all times in a planet that teems with potential - with 'the virtual'. 
But as well as situating the present of the Earth against its deep past, and finding its deep past (and alternative presents) within its present, we also need to develop ways of thinking about our planet's deep future. In What is the future? (2016), John rejected two common approaches to the future: one that focuses on individual rationality and agency, and another that sees the future as more or less determined by fixed structures. Instead, he insisted on the need to regard social futures as the product of self-organising complex adaptive systems, which pass through phase transitions and thereby behave in non-linear ways. This insight applies a fortiori to planetary futures. The Earth regarded in the way I have sketched above - as planet, as volumetric, as differential and as geohistorical - is one whose future cannot be known in advance. However, at the same time, these dimensions of the planetary turn can help us to discern the possibilities latent within our own time, and perhaps better steer towards more desirable futures for our own, precious home planet.

John Urry remained committed to the discipline of sociology to the very end, but showed us a way of doing sociology that was not afraid of embracing very different forms of knowledge and ways of knowing. He also showed a wider readership how sociology could perform an important role in providing an overall framework for highly interdisciplinary analyses of major contemporary issues, in a way that combined scholarly depth and range with passion and urgency. In so doing he developed an inspiring vision of a sociology that was both more capacious and more engaged. In order to continue and further develop that legacy, and in order to fully and responsibly inhabit the Earth, we still need to develop the planetary turn. John has left us with that task.

\section{$\underline{\text { References }}$}

Clark, Nigel (2011) Inhuman Nature: Sociable Life on a Dynamic Planet, London: Sage.

Connolly, William E. (2017) Facing the Planetary: Entangled Humanism and the Politics of Swarming, Durham, NC: Duke University Press.

Hamilton, Clive (2017) Defiant Earth: the Fate of Humans in the Anthropocene, 1 edition, Cambridge: Polity.

Latour, Bruno (2017) Facing Gaia: Eight Lectures on the New Climatic Regime, Cambridge: Polity. Tsing, Anna Lowenhaupt, Heather Anne Swanson, Elaine Gan and Nils Bubandt (eds) (2017) Arts of Living on a Damaged Planet: Ghosts and Monsters of the Anthropocene, Minneapolis: University of Minnesota Press. 